\title{
Measles-Mumps-Rubella Vaccination of Patients with Egg Allergy: One Center Experience
}

\author{
(1) Pınar Yılmazbaş ${ }^{1}$, (1) Esra Yücel2 2 (1) Deniz Özçeker² \\ 1 University of Health Sciences Turkey, Prof. Dr. Cemil Taşçığlu City Hospital, Clinic of Pediatrics, Division of Well-Child Unit, Istanbul, Turkey \\ 2 University of Health Sciences Turkey, Prof. Dr. Cemil Taşçığlu City Hospital, Clinic of Pediatrics, Division of Pediatric Allergy Unit, İstanbul, Turkey
}

\section{Abstract}

Objective: Measles-Mumps-Rubella (MMR) vaccine is a live vaccine. Measles and mumps are cultured in chick embryo fibroblasts, and rubella is cultured in human diploid cell culture. MMR vaccine contains egg protein and there are concerns among health care providers while practicing this vaccine in children with history of egg allergy in primary health centers. In this study we share the clinical characteristics and MMR vaccination experiences of cases with egg allergy, who applied to well-child care and allergy-immunology outpatient clinics.

Methods: Cases who had egg allergy and who were referred to well-child care and allergy-immunology outpatient clinics for vaccination between January 2017 and September 2018 were included in the study. The cases were firstly evaluated by a pediatric allergy-immunology specialist and egg allergy was confirmed as a diagnosis. Families were informed about possible side effects. The cases were kept under clinical supervision for at least 1 hour after vaccination.

Results: Sixty-one cases with egg allergy were included in the study. Twenty-eight (45.9\%) of them were female. None of the cases had allergic reactions after MMR vaccination. The average time of vaccination of 52 cases who reached the allergy-immunology outpatient clinic before 1 year of age and were examined here was 379 days. Nine cases were directed by the primary health center for vaccination at the age of 1 year. The average time of vaccination of these 9 cases was 400 days.

Conclusion: It is seen that MMR vaccination can safely be applied to the cases with egg allergy by taking routine precautions. It is important to train the physicians working in primary health centers about allergic reactions that may develop after vaccinations in order to prevent anaphylaxis cases and to prevent delays in vaccinations.

Keywords: Vaccination, egg allergy, Measles-Mumps-Rubella vaccine

\section{INTRODUCTION}

Routine vaccination is a very important public health practice that reduces the mortality and morbidity of many infectious diseases (1). Vaccines contain active antigens, conjugating antigens, preservatives, stabilizers, antimicrobial agents, adjuvants, and culture media (2). Gelatin which is used as a stabilizer in vaccines, neomycin, polymyxin B and streptomycin added to prevent vaccine contamination are the most known allergic vaccine components. The Measles-Mumps-Rubella (MMR) vaccines are live vaccines containing virus strains. Vaccinated mumps and measles strains are produced in chicken embryo tissue culture, while rubella strain is produced in human diploid cells. Therefore, there is egg protein in the MMR vaccine, but it is at a picogram level and is too low to cause an allergic reaction (3-5).

The most common acute allergic reactions after vaccination are IgE-mediated type 1 hypersensitivity reactions, with an average incidence of 0.22/100,000 doses (6,7). It has been determined that $31 \%$ of the vaccination caused allergic reactions occur with the first vaccination. In patients with moderate to severe egg

Phone: +90 5353217433 E-mail: drpinary@yahoo.com ORCID ID: orcid.org/0000-0002-1283-1712

Cite this article as: Yılmazbaș P, Yücel E, Özçeker D. Measles-Mumps-Rubella Vaccination of Patients with Egg Allergy: One Center Experience. Eur Arch Med Res 2020;36(3):162-5

๑Copyright 2020 by the University of Health Sciences Turkey, Prof. Dr. Cemil Taş̧ığlu City Hospital European Archives of Medical Research published by Galenos Publishing House. 
allergy, no relationship was found between allergic reaction after MMR vaccine and skin prick test. First of all, hypersensitivity reactions that occur after the MMR vaccine are thought to occur due to non-egg proteins in the vaccine $(2,8,9)$.

Studies have shown that if there is accompanying asthma in cases with egg allergy, it poses a risk for anaphylaxis that may develop after vaccination $(4,10,11)$. In addition, it is stated that performing skin prick test before vaccination increases the risk of allergic reactions that may develop (12).

\section{METHODS}

Cases with egg allergy were followed up in the pediatric allergy-immunology outpatient clinic and referred to the normal pediatric outpatient and pediatric allergy-immunology outpatient clinic to be vaccinated between January 2017 and September 2018 are cases were evaluated retrospectively. The cases were primarily assessed by a child allergy-immunologist. In the cases, the diagnosis of egg allergy was made with a history of reaction associated with egg consumption, a blistering of 3 $\mathrm{mm}$ with egg yolk and/or egg white in the skin prick test or egg specific IgE above $0.35 \mathrm{kU} / \mathrm{L}$. In cases with a suspected history, a nutrient loading test was performed with eggs and patients with positive reactions were considered to have egg allergies.

The patients' families were informed about possible side effects. Vaccinations of 2 cases with a history of anaphylaxis with food intake and 5 cases with a history of angioedema were vaccinated under observation for 2 hours. Other cases were kept under observation for at least 1 hour after vaccination and families were informed after vaccination and released.

For this study, ethics committee approval was obtained from the Clinical Research Ethics Committee of Okmeydanı Training and Research Hospital (approval date: 19.02.2019 no: 1142). Since our study was a retrospective study, patient consent was not obtained.

\section{Statistical Analysis}

SPSS 22.0 package program was used in the statistical analysis of the data, the results were expressed using the mean \pm standard deviation, median (minimum value-maximum value) and number (\%) depending on whether the data were parametric. Kolmogorov-Smirnov test was used to evaluate the suitability of quantitative data for normal distribution.

\section{RESULTS}

Sixty one cases with egg allergy were included in the study. Twenty eight (45.9\%) of the cases were female and 33 (54.09\%) were male and the onset of allergic symptoms that developed was 1 month at the earliest, and atopic dermatitis was developed as urticaria at the latest 11.5 months (Table 1). In 25 of the 61 cases, there was cow's milk and/or multiple food allergies along with egg allergies (Table 2). Egg specific IgE and immunoglobulin E levels of the patients are shown in Table 2.

The average of the days of vaccination of 52 cases who reached the child allergy policlinic before 1 year of age and were examined here was 379 days. Nine cases were directed to our hospital to be vaccinated by the family health center when the vaccination age of 1 year came. The average time of vaccination for these 9 cases was 400 days.

None of the 61 cases with detected egg allergy and vaccinated had any reaction with MMR vaccine. In one case, urticarial rash developed at the application area 15 minutes after varicella vaccination, it was observed that the rash resolved

Table 1. Demographic data of the cases and clinical findings in admission to the hospital

\begin{tabular}{|l|l|l|}
\hline & $\begin{array}{l}\text { Average } \pm \text { standard } \\
\text { deviation (median) }\end{array}$ & $\begin{array}{l}\text { The smallest - } \\
\text { the largest }\end{array}$ \\
\hline $\begin{array}{l}\text { Age when allergy first } \\
\text { appeared (months) }\end{array}$ & $\begin{array}{l}5.16 \text { months }+2.1 \\
\text { months }\end{array}$ & $1-11.5$ months \\
\hline $\begin{array}{l}\text { Age when applied to } \\
\text { the hospital (months) }\end{array}$ & $\begin{array}{l}8.23 \text { months }+2.1 \\
\text { months }\end{array}$ & $3-13$ months \\
\hline Vaccination age (days) & $383+21.46(375)$ & $365-454$ \\
\hline $\begin{array}{l}\text { Clinical picture in } \\
\text { hospital admission }\end{array}$ & $\mathbf{n}$ & $\%$ \\
\hline Anaphylaxis & 2 & 3.2 \\
\hline $\begin{array}{l}\text { Urticaria and } \\
\text { angioedema }\end{array}$ & 25 & 40.9 \\
\hline Atopic dermatitis & 30 & 49.1 \\
\hline Proctocolitis only & 4 & 6.5 \\
\hline
\end{tabular}

Tablo 2. Other accompanying food allergies, laboratory findings

\begin{tabular}{|l|l|l|}
\hline & $\mathbf{n}$ & $\%$ \\
\hline Another accompanying food allergy & 25 & 40.9 \\
Cow's milk allergy & 21 & 34.4 \\
Multi food allergy & 4 & 6.5 \\
\hline Laboratory values & & \\
Egg yolk sp IgE $>0.35$ & 44 & 72.1 \\
Egg white sp IgE $>0.35$ & 58 & 95.08 \\
Number of patients had egg loading test & 20 & 32.7 \\
\hline & Median & The smallest \\
& & - the largest \\
\hline Serum total IgE (kU/L) & 40 & $0-564$ \\
Egg yolk specific IgE (kU/L) & 0.40 & $0.01-38.0$ \\
Egg white specific IgE (kU/L) & 1.23 & $0.05-74.9$ \\
\hline IgE: Immunglobulin E & \multicolumn{2}{|l}{} \\
\hline
\end{tabular}


spontaneously within 1 hour, and was kept under observation for 4 hours.

\section{DISCUSSION}

In 1st Level Health Institutions, hesitation is experienced in vaccination of cases with egg allergy with MMR vaccine, cases are referred to 3 rd Level Health Institutions and vaccination times are delayed. There are also reports from our country regarding allergic reactions developing after vaccination of children with milk and egg allergies in the form of a case report $(13,14)$. In our study, while there is no delay observed on the vaccination time of the patients who applied to our clinic due to egg allergy before their vaccination time, it is seen that the age of 1 year vaccines are delayed in 9 cases where egg allergy is questioned when it is time for the 1 year vaccination.

Khakoo and Lack (4) stated that the amount of egg protein in MMR vaccines is very low, they do not expect allergic reactions that will develop with the vaccines, even the skin puncture test, but those who have serious symptoms should be vaccinated under hospital conditions. In the study of Aickin et al. (15) they did not see a reaction with the vaccine in cases with positive skin puncture test, so they stated that the skin prick test cannot predict the allergy that will develop with the vaccine. Nakayama et al. (16) reported the reaction after 366 MMR vaccines, in 34 of these cases developed anaphylaxis. From 27 of these anaphylaxis cases, serum specific IgE could be examined and sp IgE was positive against gelatin in 25/27 (93\%) cases and it was shown that anaphylaxis occurred as a result of gelatin allergy. Upon this publication, gelatin has been removed from vaccines in Japan since 1998 and allergic reactions have almost disappeared after the MMR vaccine $(17,18)$. The British Society of Allergy and Clinical Immunology guideline recommends that all children with egg allergy be vaccinated in primary health care facilities, but the children with anaphylaxis are evaluated by the allergist $(19,20)$.

When we look at the 2018 circular of the Republic of Turkey Ministry of Health's Extended Immunization Program, it says "Anaphylactic reaction developing against a vaccine component creates definitive contraindications for all vaccines containing this substance". For MMR/Measles vaccines; the same circular states that the presence of an anaphylactic or anaphylactoid reaction against eggs (egg allergies other than anaphylaxis are not prevented) is a definite contraindication for these vaccines (21).

When we look at the MMR-II ${ }^{\circledR}$ vaccine package insert of the vaccines in our country; it states that if there is an anaphylactic or anaphylactoid reaction against eggs (egg allergies other than anaphylaxis are not prevented), there are certain contraindications (22).

In Priorix ${ }^{\circledR}$ vaccine package insert, it states that individuals with a history of anaphylactic, anaphylactoid or other rapidly developing reactions after eating eggs may be at increased risk for sudden hypersensitivity reactions after vaccination, although these types of reactions are very rare. People who have experienced anaphylaxis after eating eggs should be vaccinated very carefully with the necessary anaphylaxis treatment ready for this type of reaction (23).

In 61 cases with egg allergy in our clinic, no allergic reaction was observed after vaccination of the MMR, and in accordance with other studies, it was observed that the MMR vaccine can be safely administered in cases with egg allergy. However, it can be seen that anaphylaxis cases that may develop after both MMR and other vaccines cannot be prevented only by questioning egg allergy. Therefore, it is necessary to observe the cases for at least 60 minutes after each vaccination and ensure that the healthcare professionals working in the primary health care institution are competent to recognize and interfere with anaphylaxis (6).

Limitations of our study; since the data is retrospectively collected, there is a child immunology-allergy clinic in our center, and the patients who are followed are directed when it is time for the vaccination, we think that the vaccination times do not reflect the vaccine delays that may occur in our society.

\section{CONCLUSION}

In our study, no allergic reaction was observed after the MMR vaccine in cases with egg allergy. As suggested in many guides, we think that these cases can be vaccinated in primary health care facilities. However, in order to avoid delays in vaccination of allergic patients and to recognize the anaphylaxis cases that may develop after all vaccinations, we think that in-service training should be provided to healthcare professionals working in primary care institutions.

\section{Ethics}

Ethics Committee Approval: Clinical Research Ethics Committee of Okmeydanı Training and Research Hospital (approval date: 19.02.2019 no: 1142).

Informed Consent: This study was a retrospective study, patient consent was not obtained.

Peer-review: Externally peer-reviewed. 


\section{Authorship Contributions}

Surgical and Medical Practices: E.Y., D.Ö., Concept: P.Y., Design: E.Y., D.Ö., Data Collection or Processing: P.Y., D.Ö., E.Y., Literature Search: D.Ö., E.Y., Writing: P.Y.

Conflict of Interest: No conflict of interest was declared by the authors.

Financial Disclosure: The authors declared that this study received no financial support.

\section{REFERENCES}

1. Delany I, Rappuoli R, De Gregorio E. Vaccines for the 21st century. EMBO Mol Med 2014;6:708-20.

2. Chung EH. Vaccine Allergies. Clin. Exp Vaccine Res 2014;3:50-7.

3. Bruno G, Giampietro PG, Grandolfo ME, Milita O, Businco L. Safety of measles immunisation in children with IgE-mediated egg allergy. Lancet 1990;335:739.

4. Khakoo GA, Lack G. Recommendations for using MMR vaccine in children allergic to eggs. BMJ 2000;320:929-32.

5. Fina Aviles F, Campins Marti M, Martinez Gomez X, Rodrigo Pendas JA, Lushchenkova O, Pimos Tella L, et al. MMR vaccine and egg allergy. Experience in a hospital immunization unit. An Pediatr (Barc) 2007;67:362-7

6. Wood RA, Berger M, Dreskin SC. An algorithm for treat- ment of patients with hypersensitivity reactions after vacci- nes. Pediatrics 2008;122:e771-7.

7. Siegrist $C A$, Mechanisms underlying adverse reactions to vaccines. J Comp Pathol 2007;137(Suppl 1):46-50.

8. Esteghamati A, Keshtkar A, Heshmat R, Gouya MM, Salar Amoli M, Armin $S$, et al. Adverse reactions following immunization with MMR vaccine in children at selected provinces of Iran. Arch Iran Med 2011;14:91-5.

9. Andersen DV, Jorgensen IM. MMR vaccination of children with egg allergy is safe. Dan Med J 2013;60:A4573.

10. Fasano MB, Wood RA, Cooke SK, Sampson HA. Egg hypersensitivity and adverse reactions to measles, mumps, and rubella vaccine. J Pediatr 1992;120:878-81.
11. Sampson HA, Mendelson L, Rosen JP. Fatal and near-fatal anaphylactic reactions to food in children and adolescents. N Engl J Med 1992;327:3804.

12. Baxter DN. Measles immunization in children with a history of egg allergy. Vaccine 1996;14:131-4.

13. Yavuz ST, Sahiner UM, Sekerel BE, Tuncer A, Kalayci O, Sackesen C. Anahylactic reactions to measles-mumps-rubella vaccine in three children with allergies to hen's egg and cow's milk. Acta Paediatr 2011;100:94-6.

14. Uysal P, Alan Ş, Demir F, Erge D, Yenigün A. Anaphylaxis Developing after Measles Vaccine in an infant with cow's milk allergy. Asthma Allergy Immunol 2017;15:171-4

15. Aickin R, Hill D, Kemp A. Measles immunisation in children with allergy to egg. BMJ 1994;309:223-5.

16. Nakayama T, Aizawa C, Kuno-Sakai H. A Clinical analysis of gelatin allergy and determination of its casual relationship to the previous administration of gelatin-containing acellular pertussis vaccine combined with diphteria and tetanus toxoids. J Allergy Clin Immunol 1999;103:321-5.

17. Carapetis JR, Curtis N, Royle J. MMR immunisation. True anaphylaxis to MMR vaccine is extremely rare. BMJ 2001;323:869.

18. Kuno-Sakai H, Kimura M. Removal of gelatin from live vaccines and DTaP-an ultimate solution for vaccine-related gelatin allergy. Biologicals 2003;31:245-9

19. Clark AT, Skypala I, Leech SC, Ewan PW, Dugué P, Brathwaite N, et al. British Society for Allergy and Clinical Immunology guidelines for management of egg allergy. Clin Exp Allergy 2010;40:1116-29.

20. American Academy of Pediatrics. David W. Kimberlin, MD, FAAP, ed. 2018 Red Book: Report Of The Committee on Infection Diseases 31 ed. p.51-4.

21. T.C. Sağlık Bakanlığı Genişletilmiş Bağışıklama Programı Genelgesi. Available from: https://dosyasb.saglik.gov.tr/ Eklenti/1117,gbpgenelge2008pdf.pdf?0

22. MMR II aşı Kısa Ürün Bilgisi. Available from: https://www.msd.com.tr/ static/pdf/MMR_II_SC_Enj_Icin_Liyo_Toz_Icer_Flakon_ve_Coz_Icer_ Kull_Hazir_Enj_KUB.pdf

23. Priorixaşı Kısa Ürün Bilgisi. Available from: https://www.ilacprospektusu. com/ilac/298/priorix-1-siriga-flakon 